\title{
LUCHA CONTRA LA POBREZA Y EXTENSIÓN DE LA COBERTURA SOCIAL EN COLOMBIA
}

Carlos Soto Iguarán *

\section{Resumen}

A nivel nacional, la condición de pobreza afecta a uno de cada tres colombianos y la inserción laboral no parece ser suficiente para que los hogares se ubiquen por encima de la línea de pobreza. En este contexto, y en el marco de la configuración actual del sistema de protección social en Colombia, donde la asistencia y la promoción toman un peso cada vez más preponderante, se estudian las estrategias de extensión de los programas de protección social. Dicho análisis se hace teniendo en cuenta las características del régimen de protección social y los factores que han bloqueado la universalización del aseguramiento social. Se estudian los mecanismos dirigidos a trabajadores de difícil cobertura como son los empleados domésticos y aquellos destinados a lograr un ahorro a futuro de trabajadores informales. Sin embargo, se muestra que estas estrategias avanzan marginalmente en el objetivo de universalización y de reducción de la pobreza.

Palabras clave: pobreza, trabajadores pobres, seguridad social, universalización, régimen de protección social, trabajadores domésticos, BEPS.

\section{POVERTY REDUCTION AND COVERAGE EXTENSION OF SOCIAL PROGRAMS IN COLOMBIA}

\begin{abstract}
In Colombia today, poverty affects one individual out of three. Employment does not seem to guarantee that households' income is above the poverty line. In this context and
\end{abstract}

* Doctor en economía. Docente investigador de la Facultad de Finanzas, Gobierno y Relaciones Internacionales Centro de Investigaciones y Proyectos Especiales (CIPE), Universidad Externado de Colombia, Bogotá (Colombia). carlos.soto@uexternado.edu.co

Recibido: 22 de febrero de 2016 / Modificado: 2 de mayo de 2016 / Aceptado: 3 de mayo de 2016

Para citar este artículo

Soto Iguarán, C. (2016). Lucha contra la pobreza y extensión de la cobertura social en Colombia. OPERA, 18, pp. 35-59. DOI: http://dx.doi.org/10.18601/16578651.n18.04 
considering the current framework of the social protection system, where assistance and promotion are increasingly important, strategies for extending social protection programs play an important role. The analysis considers the characteristics of social protection regime and the factors that block the universalization of social insurance, in particular, the mechanisms targeted at workers who are difficult to cover, such as domestic workers, and those aimed at improving savings of informal workers are analyzed. The effects of these strategies are too marginal to reach universal social protection and significant reduction of poverty.

Key words: Poverty, working poor, social security, universalization, social protection regime, domestic workers, BEPS.

\section{INTRODUCCIÓN}

El Plan Nacional de Desarrollo 20062010 estructuró la política social en torno a cuatro pilares: seguridad social, acceso a activos financieros, formación de capital humano y promoción social. Este último pilar, que concentra las transferencias, bienes y servicios en beneficio de los hogares e individuos considerados pobres o pobres extremos, ha tenido un aumento importante en términos de gasto. Mientras que el gasto en el componente de promoción social crece, las tasas de afiliación contributiva no progresan. De acuerdo con las cifras del Departamento Administrativo Nacional de Estadística (DANE), en el caso de las pensiones, por ejemplo, solo un tercio de los trabajadores cotizaba para su vejez en 2013. El bajo nivel de ingreso en la actualidad es un factor que contribuye a que muchos trabajadores no tengan hoy en día, y a futuro, un ingreso suficiente para asegurar un nivel de vida que satisfaga sus necesidades básicas.

Diferentes países en desarrollo y desarrollados han implementado una serie de estrategias para responder a las bajas tasas de afiliación que conciernen en particular a los individuos de bajos ingresos. Los diferentes mecanismos implementados apuntan, ya sea a incentivar el ahorro de este grupo de trabajadores, o a transferir un ingreso a aquellas personas que no están en capacidad de seguir trabajando y no tienen formas alternativas de subsistencia. En ambos casos se contribuye a disminuir los niveles de pobreza actual o de manera diferida. Los mecanismos de incentivos para cotizar al sistema de ahorro que completan o sustituyen el ahorro pensional constituyen una forma híbrida que combina la asistencia con el aseguramiento social. En Colombia existen, por ejemplo, el programa Colombia Mayor, que entrega un subsidio a los adultos mayores que no obtuvieron derecho a pensión o los Beneficios Económicos Periódicos (BEPS) que estimulan el ahorro de trabajadores de bajos ingresos para garantizar un ingreso futuro. Por otro lado, se han implementado medidas para aumentar la afiliación de trabajadores de difícil cobertura como es el caso de los empleados domésticos.

El propósito de este artículo es analizar cómo esas diferentes estrategias contribuyen a alcanzar el objetivo de universalización de los programas sociales y, por esta vía, a disminuir las tasas de pobreza de los trabajadores y de la población en general. Para tal fin, en la primera sección de este artículo se analizan los 
vínculos entre pobreza en empleo, y cómo la inserción laboral no constituye un mecanismo que permita superar la línea de pobreza. En la segunda sección, se estudia la configuración de los regímenes de protección social en países como Colombia y los factores que han truncado el proceso de universalización. La sección siguiente se centra en entender la promoción social y cómo está focalizada principalmente en individuos pobres e inactivos. Por último, la cuarta sección estudia mecanismos de extensión de cobertura destinados a trabajadores excluidos de los seguros sociales mencionados anteriormente. De esta manera, se abren pistas de reflexión sobre los requisitos para lograr mayores tasas de cobertura que permitan un ejercicio pleno de la ciudadanía en sus componentes económicos y políticos, pero también sociales.

\section{POBREZA EN COLOMBIA: ¿EL EMPLEO COMO FACTOR DE PROTECCIÓN?}

La pobreza ha tenido una clara tendencia descendente en los últimos años en Colombia, como se observa en la tabla 1. Para construir dicha información, se utilizó la línea de pobreza establecida por el DANE, que para el año 2014 correspondía a 211.807 pesos mensuales a nivel nacional. Esta cifra se contrastó con el ingreso familiar para determinar el número de individuos pobres. De igual forma, los individuos cuyo ingreso se ubica entre 1 y 1,5 en la línea de pobreza se consideraron como vulnerables.

\section{TABLA 1. INDICADORES LABORALES DE POBREZA Y VULNERABILIDAD SEGÚN CARACTERÍSTICAS INDIVIDUALES (EN PORCENTAJE DEL TOTAL DE CADA (ATEGORÍA). TOTAL NACIONAL Y 13 ÁREAS METROPOLITANAS - 2014}

\begin{tabular}{|c|c|c|}
\hline & $\begin{array}{l}13 \text { áreas me- } \\
\text { tropolitanas }\end{array}$ & $\begin{array}{c}\text { Total } \\
\text { nacional }\end{array}$ \\
\hline Población total & 21.018 .726 & 46.296 .052 \\
\hline $\begin{array}{l}\text { Población en edad de tra- } \\
\text { bajar (PET) }\end{array}$ & 17.147.216 & 36.826 .518 \\
\hline $\begin{array}{l}\text { Población económicamen- } \\
\text { te activa (PEA) }\end{array}$ & 11.648 .752 & 23.654 .481 \\
\hline Ocupados totales & 10.492 .365 & 21.503 .323 \\
\hline $\begin{array}{l}\text { Población total bajo línea } \\
\text { de pobreza }\end{array}$ & 3.338 .787 & 13.209 .722 \\
\hline Tasa de pobreza & $15,9 \%$ & $28,5 \%$ \\
\hline PET bajo línea de pobreza & 2.307 .966 & 9.317 .730 \\
\hline Porcentaje de PET & $13,5 \%$ & $25,3 \%$ \\
\hline PEA bajo línea de pobreza & 1.302 .918 & 4.890 .126 \\
\hline Porcentaje de PEA & $11,2 \%$ & $20,7 \%$ \\
\hline $\begin{array}{l}\text { Ocupados bajo línea de } \\
\text { pobreza }\end{array}$ & 1.017 .624 & 4.154.319 \\
\hline Porcentaje de ocupados & $10 \%$ & $19,3 \%$ \\
\hline Población total vulnerable* & 3.340 .142 & 8.413 .394 \\
\hline Porcentaje población total & $15,9 \%$ & $18,2 \%$ \\
\hline PET vulnerable & 2.514 .031 & 6.434 .500 \\
\hline Porcentaje de PET & $14,7 \%$ & $17,5 \%$ \\
\hline PEA vulnerables & 1.596 .940 & 3.960 .792 \\
\hline Porcentaje de PEA & $13,7 \%$ & $16,7 \%$ \\
\hline Ocupados vulnerables & 1.369 .075 & 3.525 .746 \\
\hline Porcentaje de ocupados & $13 \%$ & $16,4 \%$ \\
\hline $\begin{array}{l}\text { Tasa de pobreza en el } \\
\text { empleo (PEA bajo línea de } \\
\text { pobreza / Ocupados) }\end{array}$ & $12,4 \%$ & $22,7 \%$ \\
\hline
\end{tabular}




\begin{tabular}{|l|l|r|r|}
\hline \multicolumn{2}{|c|}{} & $\begin{array}{r}13 \text { áreas me- } \\
\text { tropolitanas }\end{array}$ & $\begin{array}{c}\text { Total } \\
\text { nacional }\end{array}$ \\
\hline \multirow{2}{*}{$\begin{array}{l}\text { Inciden- } \\
\text { cia }\end{array}$} & Población total & $15,9 \%$ & $28,5 \%$ \\
\cline { 2 - 4 } Brecha & Ocupados & $9,7 \%$ & $19,3 \%$ \\
\cline { 2 - 4 } & Población total & 5,25 & 10,84 \\
\hline \multirow{2}{*}{$\begin{array}{l}\text { Intensi- } \\
\text { dad }\end{array}$} & Ocupados & 1,42 & 3,04 \\
\cline { 2 - 4 } & Ocuplación total & 2,67 & 5,82 \\
\hline \multirow{2}{*}{$\begin{array}{l}\text { Vulnera- } \\
\text { bles }\end{array}$} & Población total & $12 \%$ & $14 \%$ \\
\cline { 2 - 4 } & Ocupados & $13 \%$ & $16 \%$ \\
\hline
\end{tabular}

* Hogares con ingresos ubicados entre 1 y 1,5 veces la línea de pobreza. Fuente: Gran Encuesta Integrada de Hogares (GEIH) del DANE. Datos 2014

Dado que se utiliza la misma metodología de Sánchez (2015) para calcular la incidencia de la pobreza, es posible verificar la continuidad de las tendencias observadas por este autor. Según datos de la Gran Encuesta Integrada de Hogares (GEIH), entre 2002 y 2012, la incidencia-que corresponde al número de individuos bajo la línea de pobreza- bajó de 49,7 a 32,9\%. En 2014, como lo muestra la tabla 1 , dicha cifra fue de $28,5 \%$. En consecuencia, se puede decir que entre 2012 y 2014 el número de pobres continuó la senda decreciente observada en la última década. De igual forma, entre 2002 y 2012, la incidencia de la pobreza para la población ocupada disminuyó en 15,8 puntos porcentuales ubicándose en $23,6 \%$. En 2014, dicho porcentaje fue de $19,3 \%$, bajando en la misma proporción que para la población total.

Por otro lado, entre 2002 y 2012, la brecha de pobreza para la población total (distancia del ingreso promedio de la población a la línea de pobreza) disminuye menos (9 puntos porcentuales) que para los empleados (7,6 puntos porcentuales). Lo mismo sucede en el caso del indicador que mide la distancia al umbral de pobreza de los más pobres (intensidad de pobreza), cuya disminución fue de 4,5 puntos porcentuales para los empleados frente a 5,8 para la población total. Esto indica, por un lado, que existen factores diferentes al empleo que han permitido dicha evolución para el conjunto de la población; sin embargo, los factores vinculados al empleo han traído mayores beneficios en términos de reducción y de afectación de la pobreza.

Entre 2012 y 2014, la tendencia descrita continuó dado que la disminución de la brecha de pobreza fue aún más marcada para los ocupados, pasando de 12,9\% a 10,8\% para la población total y de 8,4 a $3 \%$ para la población empleada. En cuanto a la intensidad, entre 2012 y 2014, disminuye en un punto porcentual tanto para la población total (5,8\% en 2014) como para los ocupados (3,2 \% en 2014). Los bajos niveles observados muestran que la severidad de la pobreza es cada vez menor, en particular en las 13 áreas metropolitanas. En la tabla 1 también de observa que, a nivel nacional, un cuarto de la población en edad de trabajar se encuentra bajo la línea de pobreza, cifra que baja al $20 \%$ de la población económicamente activa y al 19\% entre la población ocupada. Por último, se advierte que, a nivel nacional, 3,5 millones entre 21,5 millones de ocupados son considerados vulnerables. En total, el 35\% de los ocupados recibe ingresos inferiores a 1,5 veces la línea de pobreza. Estas cifras son más bajas si el universo se limita a las 13 áreas metropolitanas, reflejo del peso que tiene la 
pobreza a nivel rural. Majid (2001) calcula la tasa de pobreza en empleo para países de ingresos bajos y medios. Para ello considera la población económicamente activa bajo la línea de pobreza y la divide por la población ocupada total. Utilizando la misma metodología, en la tabla 1 se observa que para las 13 áreas dicha tasa se eleva a $12,4 \%$ y para el total nacional a 22,7\%. Según Majid, en Colombia dicha tasa era de $10 \%$ en 1986 y en 1996 se ubicó en 12,5\%.

En segunda instancia, las siguientes tablas muestran la distribución de pobres, vulnera- bles y no pobres para diferentes categorías individuales (tabla 2) y laborales (tabla 3 ). Se observa que tanto a nivel nacional como para las 13 áreas metropolitanas, la proporción de mujeres vulnerables es ligeramente mayor a la de los hombres. Con la evolución del ciclo de vida, la pobreza y la vulnerabilidad tienden a disminuir. Lo mismo sucede con los niveles de estudio. Los profesionales tienen menor número de pobres con respecto a los que solo aprobaron la primaria. Por último, la posición en el hogar influye sobre el grado de pobreza.

TABLA 2. PORCENTAJES DE POBREZA Y VULNERABILIDAD SEGÚN CARACTERÍSTICAS INDIVIDUALES (EN PORCENTAJE DEL TOTAL DE CADA CATEGORÍA). TOTAL NACIONAL Y 13 ÁREAS METROPOLITANAS - 2014

\begin{tabular}{|c|c|c|c|c|c|c|c|c|c|}
\hline & \multicolumn{4}{|c|}{13 áreas metropolitanas } & \multicolumn{4}{|c|}{ Total nacional } \\
\hline & & $\begin{array}{c}\text { Pobre } \\
(\%)\end{array}$ & $\begin{array}{c}\text { Vulnerable } \\
\text { (\%) }\end{array}$ & $\begin{array}{l}\text { No po- } \\
\text { bre (\%) }\end{array}$ & $\begin{array}{c}\text { Total } \\
(\%)\end{array}$ & $\begin{array}{l}\text { Pobre } \\
(\%)\end{array}$ & $\begin{array}{c}\text { Vulnerable } \\
(\%)\end{array}$ & $\begin{array}{l}\text { No po- } \\
\text { bre (\%) }\end{array}$ & $\begin{array}{c}\text { Total } \\
(\%)\end{array}$ \\
\hline \multirow{2}{*}{ Sexo } & Hombre & 15 & 16 & 69 & Total & 28 & 18 & 54 & 100 \\
\hline & Mujer & 16 & 16 & 68 & 100 & 29 & 18 & 53 & 100 \\
\hline \multirow{5}{*}{ Edad } & Menor de 16 & 26 & 21 & 53 & 100 & 41 & 21 & 38 & 100 \\
\hline & $17-24$ & 15 & 17 & 69 & 100 & 26 & 19 & 54 & 100 \\
\hline & $25-35$ & 14 & 15 & 72 & 100 & 24 & 17 & 59 & 100 \\
\hline & $36-50$ & 13 & 14 & 73 & 100 & 23 & 17 & 60 & 100 \\
\hline & Mayor de 50 & 9 & 11 & 79 & 100 & 19 & 15 & 66 & 100 \\
\hline \multirow{4}{*}{ Educación } & Primaria & 19 & 19 & 62 & 100 & 31 & 20 & 48 & 100 \\
\hline & Secundaria & 11 & 15 & 74 & 100 & 18 & 17 & 65 & 100 \\
\hline & Técnica y tecnológica & 5 & 9 & 86 & 100 & 8 & 11 & 81 & 100 \\
\hline & Profesional & 1 & 2 & 97 & 100 & 2 & 3 & 95 & 100 \\
\hline \multirow{4}{*}{$\begin{array}{l}\text { Posición en } \\
\text { el hogar }\end{array}$} & Jefe & 13 & 13 & 74 & 100 & 23 & 16 & 61 & 100 \\
\hline & Cónyuge & 13 & 15 & 72 & 100 & 24 & 18 & 58 & 100 \\
\hline & Hijo & 20 & 18 & 63 & 100 & 34 & 19 & 47 & 100 \\
\hline & Otro miembro & 18 & 20 & 63 & 100 & 32 & 20 & 48 & 100 \\
\hline
\end{tabular}

Fuente: Gran Encuesta Integrada de Hogares (GEIH) del DANE. Datos 2014. 
La tabla 3 muestra cómo ciertas características del mercado laboral afectan los niveles de pobreza. Los que trabajan entre $35 \mathrm{y}$
48 horas a la semana tienen menores niveles de pobreza y vulnerabilidad comparados con aquellos que trabajan más de 48 horas o menos

\section{TABLA 3. PORCENTAJES DE POBREZA Y VULNERABILIDAD SEGÚN CARACTERÍSTICAS LABORALES (EN PORCENTAJE DEL TOTAL DE CADA CATEGORÍA). TOTAL NACIONAL Y 13 ÁREAS METROPOLITANAS - 2014}

\begin{tabular}{|c|c|c|c|c|c|c|c|c|c|}
\hline & \multicolumn{4}{|c|}{13 áreas metropolitanas } & \multicolumn{4}{|c|}{ Total nacional } \\
\hline & & $\begin{array}{c}\text { Pobre } \\
(\%)\end{array}$ & $\begin{array}{c}\text { Vulnerable } \\
\text { (\%) }\end{array}$ & $\begin{array}{l}\text { No po- } \\
\text { bre (\%) }\end{array}$ & $\begin{array}{c}\text { Total } \\
(\%)\end{array}$ & $\begin{array}{c}\text { Pobre } \\
(\%)\end{array}$ & $\begin{array}{c}\text { Vulnerable } \\
\text { (\%) }\end{array}$ & $\begin{array}{l}\text { No po- } \\
\text { bre (\%) }\end{array}$ & $\begin{array}{c}\text { Total } \\
(\%)\end{array}$ \\
\hline \multirow{4}{*}{$\begin{array}{l}\text { Intensidad } \\
\text { horaria }\end{array}$} & Menos de 20 horas & 18 & 18 & 64 & 100 & 30 & 20 & 50 & 100 \\
\hline & 20-35 horas & 15 & 15 & 70 & 100 & 29 & 18 & 53 & 100 \\
\hline & $35-48$ horas & 7 & 11 & 82 & 100 & 16 & 15 & 70 & 100 \\
\hline & Más de 48 horas & 10 & 14 & 76 & 100 & 17 & 17 & 66 & 100 \\
\hline \multirow{5}{*}{$\begin{array}{l}\text { Posición } \\
\text { ocupacional }\end{array}$} & Asalariado & 5 & 11 & 84 & 100 & 9 & 14 & 77 & 100 \\
\hline & Empleado doméstico & 10 & 16 & 74 & 100 & 20 & 18 & 63 & 100 \\
\hline & Cuenta propia & 16 & 16 & 68 & 100 & 29 & 19 & 52 & 100 \\
\hline & Patrón empleador & 4 & 6 & 90 & 100 & 9 & 10 & 82 & 100 \\
\hline & No remunerado & 22 & 20 & 58 & 100 & 41 & 21 & 39 & 100 \\
\hline \multirow{3}{*}{$\begin{array}{l}\text { Mercado } \\
\text { laboral }\end{array}$} & Ocupado & 10 & 13 & 77 & 100 & 19 & 16 & 64 & 100 \\
\hline & Desempleado & 25 & 20 & 56 & 100 & 34 & 20 & 46 & 100 \\
\hline & Inactivo & 18 & 17 & 65 & 100 & 34 & 19 & 48 & 100 \\
\hline \multirow{2}{*}{ Informal } & Sí & 16 & 17 & 67 & 100 & 28 & 20 & 52 & 100 \\
\hline & No & 4 & 9 & 87 & 100 & 6 & 11 & 82 & 100 \\
\hline \multirow{9}{*}{$\begin{array}{l}\text { Rama de } \\
\text { actividad }\end{array}$} & Agricultura & 11 & 10 & 79 & 100 & 37 & 21 & 42 & 100 \\
\hline & Minería & 6 & 6 & 88 & 100 & 25 & 13 & 62 & 100 \\
\hline & Industria & 8 & 14 & 77 & 100 & 15 & 16 & 69 & 100 \\
\hline & Servicios públicos & 5 & 9 & 86 & 100 & 6 & 14 & 80 & 100 \\
\hline & Construcción & 15 & 18 & 67 & 100 & 21 & 20 & 59 & 100 \\
\hline & Comercio & 13 & 15 & 72 & 100 & 19 & 18 & 63 & 100 \\
\hline & Transporte & 11 & 14 & 75 & 100 & 19 & 18 & 63 & 100 \\
\hline & Financiero & 7 & 9 & 84 & 100 & 10 & 10 & 80 & 100 \\
\hline & Servicios & 6 & 10 & 84 & 100 & 11 & 12 & 77 & 100 \\
\hline
\end{tabular}

Fuente: Gran Encuesta Integrada de Hogares (GEIH) del DANE. Datos 2014. 
de 20 horas. Lo mismo sucede con los asalariados y los patrones frente a los trabajadores por cuenta propia y los no remunerados. El $10 \%$ de los ocupados son pobres, frente al $25 \%$ en el caso de los desempleados. Con respecto a estos últimos, los inactivos tienen mayor proporción de individuos no pobres. Las diferencias entre trabajadores formales e informales son claras, dado que estos últimos tienen mayor proporción de pobres y vulnerables y menor porcentaje de no pobres. Por último, a nivel nacional las ramas con mayor número de pobres son la agricultura, la minería, la construcción y el comercio. Al otro extremo, los servicios públicos y las actividades financieras tienen el menor número de no pobres.

La información presentada pone de relieve la importancia de la inserción laboral y de los factores que contribuyen a la misma en los niveles de pobreza. Al respecto, López (2010) describe la evolución del empleo calificado y no calificado entre la última década de los ańos noventa y la primera década del 2000. Según López, el empleo asalariado con educación secundaria, junto con el empleo asalariado o independiente con estudios superiores (completos o no) -que el autor denomina empleo moderno- tendió al alza en el periodo reseńado en las siete ciudades principales. En porcentaje de la población en edad de trabajar (РET), el empleo moderno creció más de 5 puntos porcentuales entre el 2000 y el 2009, y su aumento ha sido impulsado de manera continua por el componente de educación superior. Por otra parte, el empleo informal (medido según los trabajadores no asalariados sin educación superior) aumentó a finales de las década del 2000 (21\% de la PET) a niveles superiores de los alcanzados tras la crisis $(20,3 \%$ de la PET).

En particular, López (2010, p. 5) resalta el aumento de un "excedente laboral no utilizable en el sector moderno" debido a que el mercado laboral urbano absorbe cada vez menos mano de obra sin educación superior. Si el peso de estos trabajadores disminuye en la población económicamente activa, también lo hace, y en mayor medida, como porcentaje del empleo moderno. De esta manera, los trabajadores con estudios secundarios o menos se ubican en los empleos informales más precarios y en el desempleo ${ }^{1}$. Tras la apertura económica de inicios de la década de los noventa se produce un cambio técnico en la economía colombiana que produce un sesgo contra el empleo no calificado. Como consecuencia de la introducción y el uso de nueva maquinaria disminuye el empleo formal por unidad de PIB urbano, pero mientras el empleo formal poco educado por unidad de PIB urbano disminuyó, aquel con alguna educación superior aumentó (López, 2010)².

\footnotetext{
1 Para las siete ciudades principales, a finales de la década del 2000, el $60 \%$ de estos trabajadores hacía parte de dicho excedente laboral frente al $46 \%$ en 1996 (López, 2010).

2 A pesar de los cambios reseńados, después de una caída entre 2007 y 2009, el ingreso de los trabajadores en su conjunto aumentó desde el ańo 2010, con una tendencia más marcada para los trabajadores formales que informales, y en ambos casos crecen los aportes de los trabajadores al ingreso de los hogares (López, 2014).
} 
Así como se vio en el caso de Colombia, en América Latina y el Caribe son los hogares con menores niveles educativos los que más se ven afectados por la condición de pobreza. Según el Banco Mundial (2015), a pesar de que en la región los hogares encabezados por adultos no calificados suman el $28 \%$ del total, representan el $58 \%$ de la pobreza extrema y el $40 \%$ de la pobreza moderada ${ }^{3}$. Los nivel de pobreza de estos hogares han disminuido en $20 \%$ en la última década, fenómeno que ha beneficiado al conjunto de América Latina, donde un cuarto de la población salió de la pobreza entre 2004 y 2012.

El factor detrás de dicha reducción ha sido el aumento de los ingresos labores que dan cuenta del $49 \%$ de las menores tasas de pobres entre 2008 y 2013. Según el citado estudio del Banco Mundial, los ingresos no laborales que incluyen transferencias monetarias públicas y en especie, pensiones contributivas y no contributivas, ingresos de capital, transferencias privadas y remesas contribuyeron en $39 \%$ a dicha reducción, mientras que la reducción de la tasa de dependencia (es decir, el aumento de la PET), explica el $12 \%$ en el mismo periodo. La proporción adjudicada al aumento de los ingresos laborales se entiende, a su vez, por el aumento en los niveles de formación, el cual ha sido marcado. Sin embargo, esta mayor dotación de capital humano se ha visto afectada por el hecho de que no ha habido una mayor intensidad en el uso de dicho factor, es decir, que no ha aumen- tado la participación de la fuerza laboral, en particular la de los trabajadores más pobres. En consecuencia "aunque la escolaridad ha tenido una tendencia al alza en toda la región, las familias menos acomodadas han reducido la intensidad de la utilización de su capital humano, lo que ha limitado su capacidad de beneficiarse y contribuir al crecimiento" (Banco Mundial, 2015, p. 24). El vínculo entre pobreza y empleo queda de manifiesto, destacándose en particular que el acceso al empleo no es una garantía para solventar las necesidades insatisfechas individuales y del hogar. La relación empleo-pobreza debe ser analizada en el marco de la organización de la protección social y de la universalización de los seguros, objeto de la siguiente sección.

\section{RÉGIMEN DE BIENESTAR Y UNIVERSALIZACIÓN DE LA POLÍTICA SOCIAL}

La literatura sobre el Estado de bienestar tiene una larga tradición en los países desarrollados. El influyente trabajo de EspingAndersen (1990) avanzó en la diferenciación cualitativa de los diferentes tipos de Estado que surgieron en Europa. Para ello introduce el concepto de régimen de bienestar que corresponde a arreglos institucionales que moldean las políticas sociales. Esping-Anderson resalta la existencia de tres regímenes que conciernen a tipos ideales de las configuraciones observadas en países anglosajones, escandinavos y

3 Según el Banco Mundial (2015), la pobreza moderada corresponde al porcentaje de personas con ingresos inferiores a 4 dólares diarios y, en el caso de la pobreza extrema, a ingresos inferiores a 2,5 dólares diarios. 
de Europa continental. Se diferencian a partir del grado de desmercantilización, entendido como el grado en que un individuo puede satisfacer sus necesidades sin depender del mercado, y del grado de estratificación, entendido como el nivel en que la intervención del Estado modifica las estructuras de clase y el orden social. El régimen liberal tiene un grado de desmercantilización bajo en la medida en que el acceso a bienes y servicios sociales se da principalmente por intermedio del mercado y, por ende, la estratificación se da según el poder adquisitivo de las personas. En el otro extremo, el régimen socialdemócrata desmercantiliza al máximo dado que el Estado garantiza un máximo de derechos a la mayoría de la población. Por tanto, la estratificación es mínima. Por su parte, la desmercantilización bajo el régimen corporativista-conservador se da a través del mercado laboral, por medio del tipo de ocupación y de empleo desempeñado, el cual determina igualmente el nivel de estratificación.

Esping-Andersen centra su análisis en los Estados de bienestar de tipo keynesiano que emergen durante la posguerra, a mediados del siglo xx. Dada la particularidad histórica, política y socioeconómica en la que emerge dicha configuración en Europa, es difícil hablar en el mismo sentido de Estado de bienestar en América Latina. Por tal motivo, la referencia a un régimen de bienestar adquiere mayor pertinencia en la medida en que dicho régimen toma diferentes configuraciones entre las cuales el Estado de bienestar es una entre ellas que se dio en los países desarrollados. Conceptualmente, Esping-Andersen (1999) se refiere al welfare mix entendido como "la manera combinada e interdependiente en que el bienestar es producido y asignado entre el Estado, el mercado y la familia” (1999, pp. 34-35). Este concepto permite no limitarse a la intervención del Estado en la producción de bienestar y abre la posibilidad de entender las particularidades de los países en desarrollo, donde la consolidación del Estado y de su capacidad de tributación, de regulación del mercado laboral y de garantía de mínimos sociales ha sido limitada.

Gough et al. (2004) exploran diferentes configuraciones que permiten garantizar distintos niveles de seguridad a los individuos en países en desarrollo, teniendo en cuenta las intervenciones conjuntas del Estado, el mercado y la familia. Gough, además de los Estados de bienestar (welfare state regimes), que vieron luz en los países desarrollados y que se apoyan en la generalización del empleo formal, logrando diferentes grados de desmercantilización, se refiere a la existencia de tipos ideales que denomina regímenes informales de seguridad y de inseguridad en los países en desarrollo. Bajo los informal security regime, solo los trabajadores asalariados y sus familias obtienen cierto grado de seguridad, mientras que el resto de trabajadores se encuentran sometidos a relaciones clientelistas y de jerarquía que condicionan su acceso a niveles mínimos de bienestar.

En el caso de América Latina, Barrientos (2004) considera que el régimen de bienestar que se ha desarrollado puede ser considerado "conservador-informal". Se establece, por un lado, el paralelo con regímenes corporativistaconservadores en la medida en que se da una estratificación en función de la ocupación 
laboral. Por otro lado, el apelativo informal surge del acceso limitado a instituciones formales de bienestar dada la división formal/ informal que se da en el mercado laboral (Soto Iguarán, 2011).

Varios autores se han centrado en resaltar las diferentes configuraciones que han emergido en América Latina. Por ejemplo, Mesa-Lago (1989) distingue entre los países pioneros, intermedios y tardios, tomando la fecha de introducción de los sistemas de seguridad social e indicadores de cobertura y gasto. Otros autores han procurado introducir una diferenciación menos lineal y evolutiva de los regímenes de bienestar. Por ejemplo, Martínez-Franzoni (2008) toma diferentes indicadores de mercantilización, desmercantilización y desfamiliarización (grado de independencia del individuo frente a la familia) para distinguir entre tipos ideales que denomina: state-targeted regimes, statestratified regimes e informal-familiar regimes. Una clasificación por destacar es la realizada por Filgueira (1999), en la medida en que se concentra en distinguir de manera cualitativa las diferencias entre los distintos regímenes a través de un análisis de economía política. El autor menciona la existencia de regímenes universales estratificados, duales y excluyentes.

En el marco de la discusión sobre universalización y extensión de la seguridad social en los países latinoamericanos se destaca que, independientemente de las particularidades propias a cada país y de las transformaciones que ha tenido cada régimen, el mercado laboral surge como un elemento diferenciador en las posibilidades de acceso a los sistemas de protección social. En todos los países se introdujeron formas de protección social bismarkianas relacionadas con el estatus ocupacional y, por ende, la segmentación del mercado laboral constituye un freno al acceso a los sistemas de protección social. De allí que en las tres clasificaciones citadas, las tipologías se diferencian según el grado de estratificación que produce el acceso y las barreras al empleo formal. En efecto, Mesa-Lago considera entre los indicadores para elaborar su tipología el porcentaje de la población económicamente activa, mientras que Filgueira tiene en cuenta el porcentaje de cobertura a la seguridad social. Martínez-Franzoni, por su parte, incluye el porcentaje de asalariados en el total de ocupados y el porcentaje de trabajadores independientes poco calificados.

Los altos niveles de informalidad, entendida como ausencia de protección social, reflejan a la vez un bajo nivel de la extensión de la condición de asalariado y la incapacidad del Estado a ampliar la cobertura a los trabajadores independientes y a hacer respetar la legislación laboral. Mientras que esta última se mezcla con prácticas de gestión del recurso humano por parte del sector privado que el Estado no tiene cómo impedir, la condición de asalariado toma diferentes formas y en particular tiene una condición reversible dados los niveles de movilidad elevados entre posiciones ocupacionales (independientesasalariados) y entre ocupaciones formales e informales (GREITD, 1993).

La pregunta fundamental para los regímenes de protección social es cómo extender la cobertura de los seguros sociales en el marco de un mercado de trabajo segmentado y de alta precariedad laboral. Al respecto, Lautier 
(2005a) destaca las razones por las cuales en América Latina se truncó la universalización progresiva de la protección social. Según este autor, el principio de base de los sistemas de protección social, que se implementó en Europa y en el que se basaron los países latinoamericanos, es la financiación de la cobertura mutual de los riesgos sociales a partir de un porcentaje de los salarios. Dichos recursos pueden aumentar en la medida en que aumente el número de asalariados, sus salarios y la parte del salario que se socializa. Más allá de los factores de índole técnico y político, Lautier se concentra en las causas de origen social y económico para explicar la no aplicación del principio mutualista en América Latina ${ }^{4}$. La primera es una alta jerarquía de los salarios que incentiva a los que están arriba de la escala salarial a preferir sistemas de seguridad social separados. La segunda es la distribución desigual de las ganancias de productividad que impidió un financiamiento amplio y creciente de las prestaciones sociales. La tercera razón se relaciona con el hecho de que el aumento de la proporción de asalariados se hizo sin una extensión proporcional de la base contributiva, transfiriendo el financiamiento del gasto social al presupuesto general. Teniendo en cuenta estos obstáculos, el autor hace una propuesta normativa según la cual: "el primer criterio para juzgar la eficacia potencial de una medida de política social en materia de lucha contra la pobreza es saber si constituye o no un avance en la aplicación del principio de mutualización" (Lautier, 2005a, p. 101)5

A la luz de esta afirmación, en las secciones siguientes se analizan las evoluciones recientes de la política social en Colombia, así como ciertas estrategias de ampliación de la cobertura, con el fin de investigar en qué medida permiten avanzar hacia el objetivo de universalización.

\section{UNIVERSALIZACIÓN Y ESTRUCTURA DE LA POLÍTICA SOCIAL}

Tras el fracaso de las redes de protección, introducidas en los países en desarrollo en la década de los noventa, como estrategia para asegurar un ingreso básico a individuos de ingresos bajos o como mecanismos de protección contra los choques económicos, se da un cambio de paradigma en la década siguiente, bajo el cual la lucha contra la pobreza se vuelve central (Merrien, 2013).

La manera de reducir la incidencia de la pobreza y de lograr los Objetivos de Desarrollo del Milenio, adoptados por las Naciones Unidas en el año 2000, se centra para el Banco Mundial en el manejo social del riesgo (MSR). La concepción de protección social adoptada por esta institución se basa entonces en el ma-

\footnotetext{
4 Desde el punto de vista técnico se refiere al control de la evasión y, desde el punto de vista político, al rechazo de ciertos grupos (trabajadores independientes y patrones de bajos ingresos) a pagar tributos cuyos beneficios son intangibles.

5 Cabe anotar que, para Lautier, las políticas sociales surgen para luchar contra la vulnerabilidad, es decir, contra las causas sociales de la pobreza. De esta manera, la reducción de la pobreza es la consecuencia de la lucha contra la vulnerabilidad por medio de los seguros sociales.
} 
nejo de riesgos cuyo objetivo es el de "mejorar el bienestar individual y social en un entorno estático, contribuir al desarrollo y crecimiento desde una perspectiva dinámica y reducir la pobreza de manera efectiva y duradera" (Holzmann y Jorgensen, 2003, p. 8). Los riesgos se categorizan según sus causas, que pueden ser naturales, políticas, económicas, ambientales o sociales, o estar relacionadas con la salud o el ciclo de vida y, según su nivel, que pueden micro si solo afectan al individuo o macro en la medida en que tienen una afectación colectiva $^{6}$.

Los individuos pobres no solo están más expuestos a los diferentes tipos de riesgo, sino que además están en menor capacidad de hacerles frente. Las estrategias pueden ser de origen informal, como los dispositivos comunitarios de ahorro; mecanismos de mercado, como los seguros privados; o públicos, como los seguros colectivos. De esta manera, la protección social se convierte en brindar las herramientas para el MSR que permitan a los individuos enfrentar los diferentes tipos de riesgo y emprender actividades más rentables que mejoren sus ingresos.

En Colombia, el conpes 3144 de 2001 institucionalizó el manejo social del riesgo adoptando la concepción del Banco Mundial en materia de estrategias de MSR, conformando el "Sistema Social de Riesgo (SSR) dirigido a prevenir y mitigar los efectos adversos que se presentan sobre la población vulnerable durante episodios de recesión económica”.
La prevención y la mitigación intervienen antes de que se produzcan los riesgos; mientras que en el primer caso se buscar reducir la probabilidad de que un riesgo disminuya el bienestar y el ingreso, en el segundo se busca reducir su efecto potencial. En tercer lugar, la superación interviene posterior a la ocurrencia del riesgo y su objetivo es, como su nombre lo indica, superar su impacto (Holzmann y Jorgensen, 2003).

La organización actual del sistema de protección social en Colombia refleja la operacionalización de dicho enfoque. La Red de Apoyo Social, creada en el año 2000, implementó los programas de Familias en Acción, Jóvenes en Acción y Empleo en Acción inaugurando un enfoque de la política social centrado en transferencias a la demanda, condicionadas a la realización de acciones específicas y focalizadas en grupos poblaciones particulares con el fin de luchar contra la pobreza y mejorar la gestión del riesgo.

A partir del Plan de Desarrollo 20062010 (Estado Comunitario: desarrollo para todos), se introduce, en contraste con los anteriores, el concepto de promoción social, que se define como "una acción o conjunto de intervenciones dirigidas a impulsar una persona o un grupo de personas de la sociedad que carece de los medios y oportunidades para manejar una situación de privación o vulnerabilidad" (DNP, 2008, p. 11). Sin embargo, se subraya la diferencia con la asistencia en la medida en que la promoción no se limita

6 Por ejemplo, para los riesgos de origen económico una afectación micro puede ser el desempleo y una afectación macro una crisis financiera. 
a una acción puntual de corto plazo. "Su objetivo es de expandir las oportunidades de los pobres y de los vulnerables, no solucionar temporalmente su problema de necesidades mínimas, sino promover la expansión de sus oportunidades, es decir, alcanzar logros en término de inclusión social y generación de ingresos propios" (DNP, 2007, p. 142).

El sistema de protección social contiene diferentes componentes con políticas y programas que permitan que ante la ocurrencia de algún riesgo o antes de dicho evento se puedan prevenir, mitigar o superar los efectos negativos. La promoción social constituye uno de los pilares con programas que apuntan a mejorar en el corto y en el largo plazo la situación de individuos y familias previamente identificadas. Las dos intervenciones más importantes son la transferencia condicionada que se otorga bajo el programa Más Familias en acción y que en 2015 benefició a más de 2,5 millones de familias pobres, y el programa Red Unidos que, en el mismo año, facilitó el acceso a bienes y servicios sociales a alrededor de 1,5 millones de hogares en pobreza extre$\mathrm{ma}^{7}$. Otro pilar del sps es la seguridad social integral que incluye los sistemas pensional, de salud y de riesgos laborales, a los cuales se accede por medio de cotizaciones obreropatronales. En la década de los noventa se introdujeron lógicas de mercado para la gestión de estos subcomponentes. El sistema de riesgos laborales brinda protección a trabajadores, que escogen entre diferentes aseguradores, en caso de la ocurrencia de enfermedades o accidentes laborales. Los trabajadores que cotizan pueden igualmente escoger entre aseguradores y prestadores públicos y privados de salud (régimen contributivo), mientras que los individuos no asegurados se benefician de un régimen especial en el cual reciben un subsidio que da acceso a prestaciones de salud (régimen subsidiado). Además de la competencia entre aseguradores y prestadores por captar clientes, se introdujo un sistema de subsidio de la demanda, bajo el supuesto de que iba a reducir costos aumentando la eficiencia. En el caso de las pensiones, se creó un sistema mixto conservando el sistema público por repartición e introduciendo la posibilidad de escoger entre diferentes fondos privados, bajo una lógica de capitalización individual.

Adquirir y mantener un stock de capital humano constituye una buena estrategia de gestión del riesgo, de allí que otros dos pilares importantes del sps sean el Sistema nacional de formación para el trabajo y el Sistema de protección al desempleo, cuyo fin último es activar a las personas en el mercado laboral. En el primer caso, se trabaja en pro de brindar capacitaciones y formaciones, certificar competencias y hacer intermediación laboral. En el segundo caso, se administran las cesantías, el seguro y los subsidios al desempleo. De la misma manera, el MSR es posible a través del acceso a activos, otro componente del sps, que se da por medio del acceso a servicios financieros y seguros, y por intermedio de

\footnotetext{
7 Información suministrada, respectivamente, por el Departamento para la Prosperidad Social y la Agencia Nacional para la Superación de la Pobreza Extrema.
} 
créditos para la compra de vivienda o para el emprendimiento.

La consolidación del MSR y de la promoción social en el seno del sistema de protección social colombiano se refleja en la evolución reciente del gasto social. Rodríguez (2014) propone una agregación del gasto público social tomando la clasificación funcional del gasto en Colombia. De las 12 categorías de gasto, 7 se contabilizan como gasto social, a saber: medio ambiente, vivienda y espacio público, salud, recreación, deporte, cultura y comunicación, educación y protección social. Como se observa en la figura 1, este último rubro representa el $54 \%$ del gasto social total en 2014, seguido por educación (21\%) y salud $(20 \%)$. Como porcentaje del piB esto representa, respectivamente, $7,7,3,05$ y $2,86 \%$.

En una segunda instancia, Rodríguez desagrega el gasto de protección social (clave funcional del gasto público en trabajo y seguridad social). En la figura 2 se observa el peso de los diferentes componentes del gasto en protección social para los años 2004 y 2014. Las pensiones absorben más de las dos terceras partes, a pesar de una disminución de 7 puntos porcentuales en 2014. Es importante anotar el aumento de los subsidios a las familias en 2 puntos porcentuales entre esos dos años $y$, en particular, de 6 puntos porcentuales de la atención a población vulnerable. En dicho periodo, este último gasto pasó de 0,25 a $0,77 \%$ del рів. Dentro de este rubro se destacan en particular los programas Familias en Acción y la Red Unidos (antes Juntos) junto con la reparación a víctimas que representan, respectivamente, 36 y $26 \%$ del gasto total en atención a población vulnerable.

Los otros gastos de protección social pasan del 1 al $6 \%$ del gasto de protección social, alcanzando $0,45 \%$ del PIB en 2014, frente a $0,07 \%$ en 2004 . Este aumento se explica en particular por el gasto en prevención $\mathrm{y}$ atención de desastres, y por el aumento de otros programas asistenciales en beneficio de desempleados y de adultos mayores. Aunque

FIGURA 1. GASTO PÚBLICO SOCIAL POR CLAVES FUNCIONALES COMO PORCENTAJE DE GASTO PÚBLICO SOCIAL (2014)

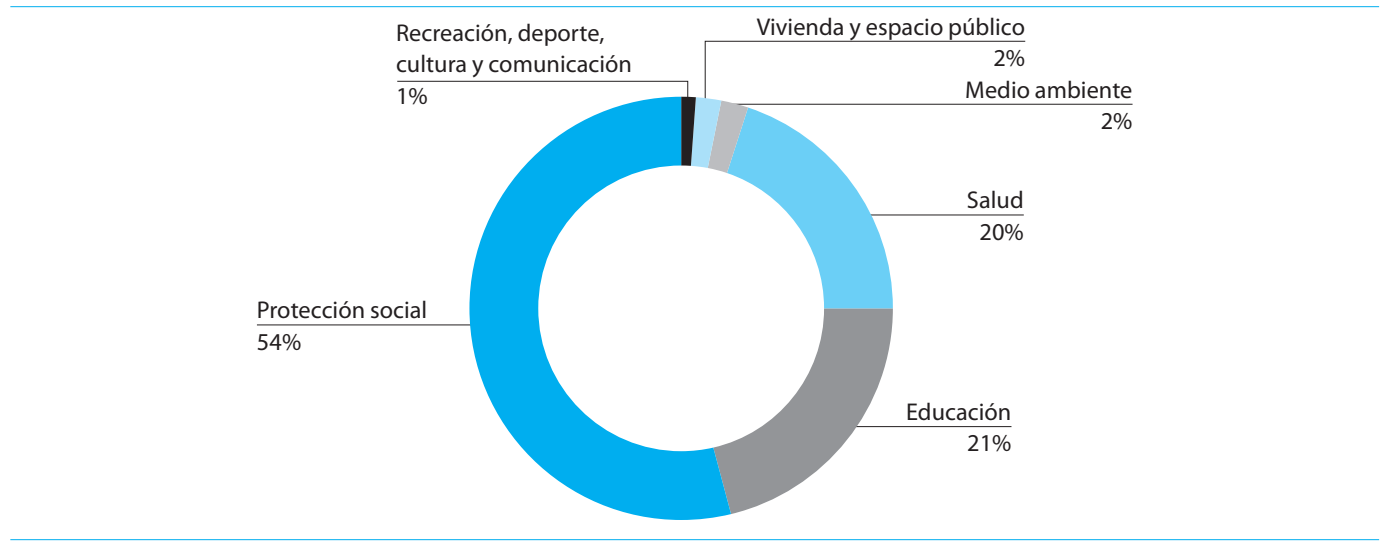

Fuente: elaboración del autor con base en Rodríguez (2014) 
FIGURA 2. GASTO EN PROTECCIÓN SOCIAL POR TIPO DE GASTO, COMO PORCENTAJE DEL TOTAL

\section{4}

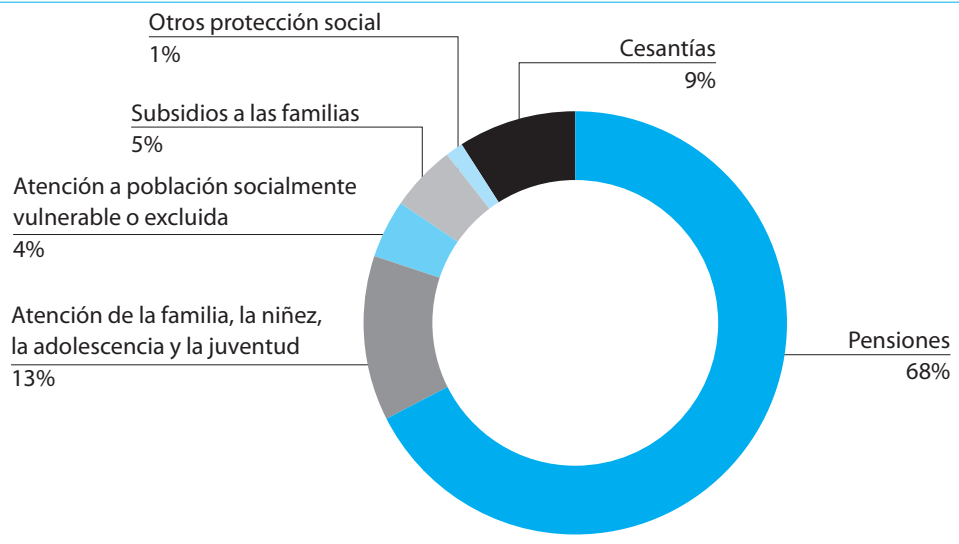

2014

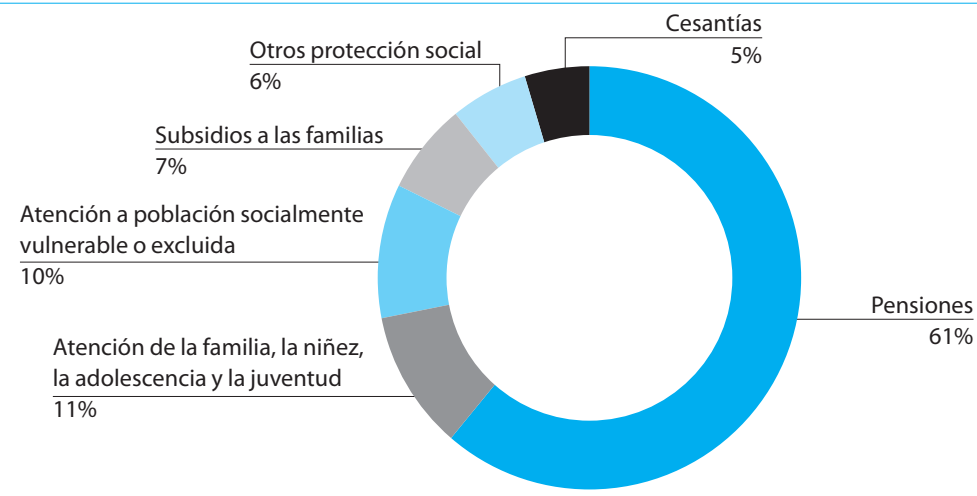

Fuente: elaboración del autor con base en Rodríguez (2014).

el gasto en beneficio de esta población es bajo, se pasa de 0,026 a $0,136 \%$ del PIB.

Estas cifras ponen en evidencia un aumento de los gastos en programas asistenciales aun cuando representan porcentajes bajos con respecto al gasto social total o al PIB. A pesar de la retórica según la cual la configuración del sistema de protección social no es asistencialista en la medida en que los beneficiarios reciben ayudas que le permiten graduarse de los programas superando su condición de pobreza, resulta claro que existen diferencias sustanciales entre este modelo focalizado y aquellos de corte universalista y solidario donde se aplica el principio mutualista.

Al respecto, Lautier (2005b) considera que a pesar de las reformas en materia de protección social introducidas en los años noventa, el sistema conservó su carácter particularista y comparatista. La diferencia radica 
en que antes de dichas reformas se daba una diferenciación entre asalariados formales, por un lado, y no asalariados o asalariados informales, dada la centralidad de la contribución salarial como mecanismo de afiliación. Bajo el nuevo esquema, el aseguramiento se logra por medio del empleo, por lo cual este no ha perdido su centralidad; sin embargo, la diferenciación se da entre categorías de población protegida y las que no lo están. Para los no asegurados existe un sinnúmero de transferencias y de programas asistenciales que se adaptan a las características de la población beneficiaria.

Bajo esta configuración, surge una diferencia con respecto al concepto de ciudadanía. La concepción que emerge en Europa en el siglo xix lleva a que la protección social sea el vehículo de los trabajadores pobres para el ejercicio de sus derechos políticos. Al equilibrar las relaciones asimétricas entre empleadores y trabajadores, garantizando a estos últimos derechos políticos, sociales y económicos, el Estado contribuye a la consolidación de una "ciudadanía plena" (Lautier et al., 1991). En un sistema focalizado en los más pobres, bajo la concepción del manejo social del riesgo, la ciudadanía se concibe más a partir del ejercicio de derechos civiles y políticos que del de derechos sociales. Así, la protección social se concibe de manera tal que "debe garantizar la posibilidad, para aquellos que pueden, de la valorización de los capitales individuales en mercado, al tiempo que se protege contra grandes riesgos" (Lautier, 2005b, p. 3). Se configura una ciudadanía del consumidor al cual se le otorga el derecho de consumir bienes y servicios en un mercado.

La protección social se configura, entonces, en torno a una dicotomía entre aseguramiento y asistencia, tal como se evidenció en el caso colombiano a partir de los cambios recientes en la materia. El rol del mercado se vuelve central en la medida en que asegurados $\mathrm{y}$ asistidos consumen bienes y servicios en un mercado de aseguradores y prestadores, como en el caso de la salud. En el caso del mercado laboral, es necesaria la existencia de mercados flexibles y, por ende, la eliminación de cualquier distorsión que aumente los riesgos de desempleo $^{8}$. Para Giraldo (2007), esto supone la eliminación de garantías sociales como el salario mínimo, las primas o la estabilidad del empleo, lo cual crea una lógica diferente a la concepción que tenía la protección social en sus inicios, cuyo objetivo era precisamente el de proteger a los individuos frente a las vicisitudes del mercado. Es a lo que Karl Polanyi se refiere como la desmercantilización.

El énfasis en la lucha contra la pobreza, justificado bajo la necesidad de beneficiar a los más pobres en un contexto de escasez de

8 En palabras de Holzman y Jorgensen: "las intervenciones preventivas de la protección social normalmente están vinculadas a medidas para reducir los riesgos en el mercado laboral, principalmente el riesgo de desempleo o subempleo o de bajos salarios por baja capacidad o mercados laborales de deficiente funcionamiento. Estas involucran estándares laborales y el (mal) funcionamiento del mercado laboral provocado por una discordancia en las capacidades de los trabajadores y la demanda, malas regulaciones del mercado laboral u otras distorsiones" (2003, p. 18). 
recursos, otorga un rol residual a las políticas sociales y se aleja entonces de una concepción universalista y mutualista. Las políticas asistenciales y de promoción van dirigidas en particular a pobres extremos y en su mayoría inactivos. Surgen al respecto dos preguntas: ¿En qué medida las políticas y los mecanismos implementados en la actualidad contribuyen a avanzar en el proyecto de universalización? ¿En qué medida dichas políticas favorecen a los trabajadores pobres? Se analizan a continuación las medidas implementadas en favor de una categoría ocupacional particular como son las empleadas del servicio y los programas de ahorro para asegurar un ingreso futuro para los trabajadores de bajos ingresos.

\section{ESTRATEGIAS DE EXTENSIÓN DE LA PROTECCIÓN SOCIAL EN COLOMBIA}

Cecchini et al. (2014) se refieren a los esfuerzos recientes para ampliar la cobertura en América Latina y el Caribe. En primer lugar, las mejoras del mercado laboral en el cual no solo juegan mayores niveles de empleo, sino también mayores controles por parte del Estado en lo relacionado con la regulación social. Por otro lado, la mayor cobertura se explica por condiciones de acceso a los programas más flexibles junto con la implementación de subsidios dirigidos a individuos antes excluidos. Por último, un tercer factor ha sido la puesta en marcha de modalidades de afiliación no contributivas.

A partir del estudio comparativo que realizan Durán Valverde et al. (2013), se construye la siguiente tabla que resume los diferentes mecanismos de extensión de cober- tura social, que según Cecchini et al. (2014) han permitido que en América Latina, entre 2002 y 2011, la población ocupada afiliada a pensiones pase de 46,1 a 55,4\% y de 54,4 a $66,4 \%$ en salud. De igual forma, que en ese mismo lapso de tiempo las personas mayores de 65 años que reciben pensión pasen de 37 a 41,9\%, y las transferencias condicionadas beneficien a $21,1 \%$ de la población total en 2012, frente a 5,7\% en 2000.

TABLA 4. ESTRATEGIAS DE EXTENSIÓN DE COBERTURA SOCIAL A NIVEL INTERNACIONAL

\begin{tabular}{|l|l|}
\hline $\begin{array}{l}\text { Categorías contributi- } \\
\text { vas diferenciadas }\end{array}$ & $\begin{array}{l}\text { Régimen contributivo dife- } \\
\text { renciado de trabajadores in- } \\
\text { dependientes con respecto } \\
\text { a trabajadores asalariados }\end{array}$ \\
\hline $\begin{array}{l}\text { Sistemas de afiliación } \\
\text { colectiva }\end{array}$ & $\begin{array}{l}\text { Firma de convenios de } \\
\text { aseguramiento colectivo } \\
\text { por parte de trabajadores } \\
\text { independientes agrupados } \\
\text { en organizaciones }\end{array}$ \\
\hline $\begin{array}{l}\text { Mecanismos especia- } \\
\text { les de recaudación de } \\
\text { contribuciones }\end{array}$ & $\begin{array}{l}\text { Instrumentos para facilitar } \\
\text { la afiliación y la recaudación } \\
\text { de las contribuciones }\end{array}$ \\
\hline $\begin{array}{l}\text { Mecanismos dirigidos a } \\
\text { la inclusión de peque- } \\
\text { ñas empresas }\end{array}$ & $\begin{array}{l}\text { Regímenes especiales para } \\
\text { fomentar la formalización } \\
\text { empresarial }\end{array}$ \\
\hline $\begin{array}{l}\text { Mecanismos dirigidos } \\
\text { a la inclusión de los } \\
\text { trabajadores indepen- } \\
\text { dientes agrícolas }\end{array}$ & $\begin{array}{l}\text { Régimen contributivo dife- } \\
\text { renciado para trabajadores } \\
\text { rurales }\end{array}$ \\
\hline
\end{tabular}

Fuente: Durán Valverde et al. (2013).

En Colombia se destaca el uso de varios de estos mecanismos. Por ejemplo, la afiliación colectiva se encuentra regulada por los decretos 3615 de 2005 y 2313 de 2006. De igual forma, la Planilla Única de Liquidación de Aportes (PILA) y el Registro Único de Aportantes permiten tanto el pago de aportes 
como un seguimiento a las personas afiliadas al sistema. Por otro lado, la Ley 1429 de 2010 buscó la formalización de empresas con menos de 50 trabajadores por medio de diferentes incentivos tributarios y contributivos. A continuación se analizan dos mecanismos que apuntan aumentar la cobertura, que pueden ser clasificados dentro del grupo de categorías contributivas diferenciadas.

En diciembre de 2012, mediante la Ley 1595, el Gobierno nacional ratificó el Convenio 189 de la Organización Internacional del Trabajo (оIт), que ofrece protección específica a los trabajadores domésticos y estipula los derechos y principios básicos que deben regir las formas de vinculación laboral y contractual para este colectivo. El Estado se ve en la obligación de legislar en pro del aseguramiento social de esta población, garantizándole el acceso y goce de los beneficios del trabajo decente (Organización Internacional del Trabajo, 2011).

En Colombia, es obligación de los empleadores afiliar a sus trabajadores al sistema de seguridad social, con el objetivo de dar acceso al conjunto de seguros y servicios sociales. Sin embargo, los trabajadores domésticos han sido excluidos de estos derechos al mantenerse su relación laboral como informal. $\mathrm{Al}$ respecto, en materia pensional se reportó en 2011 que solo el $12,8 \%$ de los trabajadores domésticos eran cotizantes activos, lo que implica un elevado nivel de no afiliación que afecta en el corto y en el largo plazo el bienestar de esta categoría de trabajadores (Ministerio de Trabajo, 2012).

La citada ley apunta entonces a aumentar el número de personas vinculadas a los diferentes servicios de aseguramiento social garantizando su igualdad laboral. Con el fin de evitar abusos laborales a esta población trabajadora, especialmente niñas y mujeres, así como la vulneración de sus derechos fundamentales, se define la edad mínima para desarrollar estas actividades laborales, lo cual contribuye además a evitar la privación de la escolaridad obligatoria. Aunque dicha relación contractual puede ser escrita o verbal, se debe establecer de manera clara la duración de la relación contractual, el tipo de trabajo que se va a realizar, las partes involucradas en la relación contractual, la remuneración, el método de cálculo de la misma y la periodicidad de los pagos, las horas de trabajo, el salario y la forma como se calculará y lo relativo a cesantías, primas y demás componentes del salario.

Los Decretos 721 y 2616 de 2013 buscan fortalecer la vinculación formal de los trabajadores domésticos haciendo énfasis en su aseguramiento social. El primero obliga a los empleadores a vincular a sus empleadas del servicio doméstico a las cajas de compensación familiar además de pagar los aportes al Sistema de Compensación Familiar con base en el salario devengado por el empleado, que no podrá ser inferior a un salario mínimo mensual vigente y el pago ( $4 \%)$ se hará a través de la planilla PILA. Por otro lado, el Decreto 2616 de 2013 tiene por objetivo establecer los parámetros para la adopción del esquema financiero y operativo, que permita la vinculación de los trabajadores dependientes que laboren por periodos inferiores a un mes a los sistemas de pensiones, riesgos laborales y subsidio familiar. Los empleados deben escoger su fondo pensional mientras que los 
empleadores escogen la administradora de riesgos y la caja de compensación.

La flexibilidad que se otorga para fomentar la afiliación de estos trabajadores radica en que se posibilita la cotización por periodos inferiores a 30 días. Para ello establece una cotización mínima semanal igual a una cuarta parte del salario mínimo mensual. Si el trabajador labora entre 1 y 7 días, se debe cotizar una semana, 2 semanas si el trabajo dura entre 8 y 14 días, hasta un máximo de 4 semanas si se laboran más de 21 días. Esto se diferencia para el resto de trabajadores para quienes, según el artículo 33 de la Ley 100 de 1993, una semana cotizada corresponde al "periodo de 7 días calendario". En cambio, los porcentajes de cotización son los mismos para todos los trabajadores. De esta manera, los empleadores deberán cotizar en beneficio de los trabajadores domésticos $12 \%$ para pensiones, $0,522 \%$ de riesgos laborales (riesgo I) y $4 \%$ para cajas de compensación. Dadas las condiciones del trabajo doméstico, con tiempos variables y posibilidad de varios contratos a la vez, el Decreto prevé la posibilidad de multiplicidad de empleadores, los cuales deberán pagar sus cotizaciones de manera independiente y a una misma aseguradora, con el fin de evitar la multiafiliación. Se estipula, además, la necesidad de hacer los cambios en la PILA para que se puedan adaptar a los montos y periodos cotizados por estos trabajadores. Por último, se permite que estos últimos transfieran sus ahorros pensionales al mecanismo de Beneficios Económicos Periódicos, explicado enseguida, como alternativa a una pensión por vejez.

El segundo mecanismo de extensión de aseguramiento que se analiza es precisamente el de Beneficios Económicos Periódicos (Beps), el cual, en efecto, está destinado a las personas que, habiendo cumplido la edad legal para pensionarse no pueden cumplir con los requisitos para acceder a una pensión. De acuerdo con la Asociación Nacional de Instituciones Financieras (2013), en el segundo trimestre de 2013 existían 8 millones de afiliados activos, correspondientes al 34,2\% de la población económicamente activa, repartidos entre el régimen de prima media (26,6\% del total) y el régimen de ahorro individual $(73,4 \%)$. Con un porcentaje tan bajo, es de esperarse que el número de personas que a futuro podrán contar con una pensión es limitado, con las consecuencias que ello pueda traer en términos de bienestar social e individual. De hecho, el porcentaje de mayores de 65 años que cobran una pensión es tan solo del $20 \%$.

Los BEPS, operacionales desde 2014, son una de las estrategias del Estado para contrarrestar esta situación. Otra de ellas es el programa Colombia Mayor, introducido en 2003 bajo el nombre de Protección Social al Adulto Mayor, el cual beneficia a personas que no tienen ingresos suficientes para subsistir y con tres ańos menos para la edad necesaria para recibir una pensión (57 años en el caso de las mujeres y 62 años para los hombres) ${ }^{9}$.

$9 \quad$ Para ser beneficiario del programa, las personas deben tener un ingreso inferior a medio salario mínimo en caso de vivir solas y menor a un salario mínimo en caso de vivir en familia. 
Mientras que los beneficiarios de este programa reciben un subsidio, los BEPS son sistema de ahorro individual y voluntario incentivado por el Estado, en la medida en que este otorga $20 \%$ del monto ahorrado por cada persona ${ }^{10}$. Es decir, que supone que la persona debe tener una fuente de ingreso que le permite hacer sus aportes de manera flexible. En efecto, las personas no están obligadas a aportar ni con una frecuencia dada ni con aportes definidos, solo en función de lo que quieran y puedan aportar en un momento dado.

De acuerdo con cálculos de la Asociación Nacional de Instituciones Financieras, el costo anual del programa Colombia Mayor, bajo el supuesto de que entre 2013 y 2050 se beneficien en promedio 2 millones de personas, sería de $0,2 \%$ anual del PIB ${ }^{11}$. En el caso de los BEPS, se calcula que alrededor de 12 millones de personas deberían pertenecer al programa para cubrir el déficit de cobertura existente. A fin de calcular el costo fiscal del programa, además de considerar un ahorro individual de 40 mil pesos al mes por individuo, ANIF tuvo en cuenta que entre los beneficiarios potenciales existen diferentes niveles de ahorro, desde los que están cerca de cumplir con los requisitos para alcanzar una pensión en los regímenes de prima media o de ahorro, hasta aquellos que han ahorrado muy poco. De esta manera, los BePs tendrían un costo fiscal de 0,12\% del PIB entre 2013 y 2050 (Clavijo et al., 2013).
En los dos casos presentados se trata de adaptar al margen ciertas condiciones para lograr dar acceso a los mecanismos existentes de protección social. En el caso de los trabajadores domésticos, se consideran tiempos de empleo bajo e irregulares, mientras que en el caso de los BEPs, cuyos beneficiarios potenciales son trabajadores pobres e informales, se considera la inestabilidad y los bajos niveles de ingreso. El objetivo es el de extender la cobertura en beneficio de trabajadores con condiciones de empleo particulares. Sin embargo, mientras que en el primer caso se trata de integrar a los que ejercen trabajos domésticos a los seguros sociales a los cuales acceden el resto de trabajadores formales, en el segundo caso es un sistema de ahorro distinto. En efecto, ninguna pensión puede ser inferior al salario mínimo, por lo que este sistema permite asegurar, a través de cuentas individuales de ahorro, ingresos a futuro así sean menores a dicho nivel. De allí que no se puedan asimilar a una pensión y tomen la apelación de beneficios periódicos.

Lautier (2005a) menciona que el mejor instrumento de lucha contra la pobreza es aquel que permite avanzar en el principio mutualista, cuya consecución depende del aumento de asalariados, salarios y contribución sobre la remuneración laboral. La amplia jerarquía salarial, la distribución desigual de las ganancias de productividad y el aumento de asalariados sin que se extienda

10 Según el consorcio Colombia Mayor, a cargo de la implementación del programa, a diciembre de 2013 el programa se implementa en más de 1000 municipios del país beneficiando a 1'250.000 personas.

11 El beneficio individual utilizado es de 62.500 pesos al mes. 
la base contributiva en la misma proporción ha jugado en contra de dicho objetivo. De manera general, se observa que en Colombia el aumento del salario mínimo integra tanto la meta de inflación como las ganancias de productividad. Sin embargo, esto cobija exclusivamente a los trabajadores formales. Por otro lado, entre las nuevas formas de empleo que se han desarrollado en los últimos ańos se cuentan aquellas que, a pesar de implantar una relación de subordinación entre empleador y empleados, responsabiliza a estos últimos por el pago de las contribuciones sociales. Es el caso, por ejemplo, de la prestación de servicios a la cual omTss (2001) se refiere como falso cuenta propismo y permite el ahorro de costos laborales para las empresas. Bajo esta figura no se avanza en el proceso de mutualidad.

Entre las estrategias de extensión de la cobertura mencionadas anteriormente (tablero 4) se cuenta la creación de categorías contributivas particulares. Durán Valverde et al. (2013) citan, entre otros casos, el ejemplo de Cabo Verde, donde los trabajadores independientes se clasifican en función de sus ingresos para determinar diferentes niveles contributivos. Esto difiere de lo aplicado en el caso de los trabajadores domésticos quienes contribuyen al mismo nivel que el resto de trabajadores y solo se da un cambio en términos de días cotizados. En el caso de los Beps, no se trata de integrar a los beneficiarios al régimen solidario, sino que se trata de cuentas de ahorro individual, que otorgan derechos inferiores a los de un pensionado de los regímenes de capitalización y de prima media. En el primer caso se deja en el seno de la relación empelado-empleador la responsabilidad de afiliación, aun cuando se reconocen las particularidades del trabajo doméstico. En el segundo caso, si en efecto se trata de cerrar la brecha en materia de cobertura existente, se hace otorgando derechos inferiores a los que acceden los trabajadores formales en materia pensional.

\section{CONCLUSIÓN}

En el presente artículo se analizó el estado de la pobreza en Colombia y sus vínculos con el empleo, resaltando en particular cómo el incremento reciente de los ingresos laborales ha sido un factor fundamental en la reducción de las tasas de pobreza. Aun así, en 2014 un trabajador ocupado sobre cinco se encontraba bajo la línea de pobreza a nivel nacional y más de un tercio de los ocupados recibe ingresos inferiores a 1,5 salarios mínimos (incluye a trabajadores pobres y vulnerables, tal como fueron definidos acá). La centralidad del empleo como mecanismo de superación de la pobreza, no solo por la vía de mayores ingresos, sino también como medio de acceso al sistema de protección social no ha perdido vigencia. Esto a pesar de que la evolución del régimen de bienestar no permitió avanzar en la universalización de las políticas sociales debido al mantenimiento de las diferencias salariales, la distribución desigual de las ganancias de productividad y un crecimiento de la base contributiva diferente al crecimiento de los asalariados. En este contexto, la lucha contra la pobreza emerge entonces como un nuevo paradigma de política social, buscando focalizar los recursos disponibles en las personas de mayor necesidad. De allí que se observen cambios progresivos en la organización de la 
política social, la cual tiene mayor énfasis en la asistencia.

Las dos estrategias de extensión de cobertura social analizadas se orientan a flexibilizar el acceso a los seguros y a otorgar una cobertura menor a la que tienen derecho los trabajadores formales. No se avanza por medio de la solidaridad y el mutualismo con el fin de aumentar la cobertura; por el contrario, en el caso de los beps se promueve el ahorro individual, estimulado por un incentivo individual. La pregunta que surge al respecto es que si por vía de mecanismos asistenciales se puede lograr, en efecto, la universalización de los derechos sociales que permitan el ejercicio de una ciudadanía plena, en sus componentes económicos, sociales y políticos.

De allí surge la pregunta de si los avances en términos de cobertura, formalización y disminución de la pobreza pueden ser sostenidos en el tiempo o si obedecen simplemente a una coyuntura económica favorable. $\mathrm{Al}$ respecto, el Banco Mundial (2015) analiza los factores detrás del incremento de los ingresos de los hogares en América Latina en la primera década del nuevo milenio. Es cierto que ha habido mayor acceso de los trabajadores poco o nada calificados a empleos formales; sin embargo, esto ha sido más una realidad para los de mayor calificación. Los primeros siguen siendo absorbidos mayoritariamente en empresas y actividades de baja productividad y remuneración, y si sus salarios han aumentado en la última década no ha sido por una reasignación sectorial o una mejor calidad del empleo. Un factor determinante fue la fuerte demanda de materias primas por parte de la China. El mejoramiento de los términos de intercambio de exportadores de recursos naturales, entre ellos Colombia, llevó a un "crecimiento general de los niveles salariales en todos los tipos de empleo" (Banco Mundial, 2015).

Ante esta evidencia, la pregunta es entonces saber qué pasará cuando esta coyuntura se revierta, como resultado de cambios en la política monetaria expansionista de Estados Unidos o de una menor llegada de capitales. Además de disminuir las oportunidades de empleo ante un freno de la demanda agrega$\mathrm{da}$, la tendencia al alza de los salarios puede verse revertida así como la capacidad fiscal del Estado para invertir en gasto social. De esta manera, las ganancias recientes en términos de reducción de la pobreza pueden perder, en particular para aquellos trabajadores vulnerables que se ubican ligeramente por encima de la línea de pobreza. De igual forma, los esfuerzos por aumentar la cobertura de programas asistenciales pueden verse truncados. De hecho, el Programa de las Naciones Unidas para el Desarrollo (PNUd, 2014) realizó, a través de un modelo de equilibrio general, la simulación de los efectos económicos y sociales de una disminución de los precios del petróleo ${ }^{12}$. El estudio muestra que ante dicho escenario, la tasa de desempleo pasaría

12 El escenario analizado supone una caída de los precios del petróleo a 60 dólares por barril, cuando en los años anteriores había alcanzado niveles superiores a los 100 dólares por barril. En febrero de 2016 dicho precio rondaba los 30 dólares. 
de nuevo a tener dos dígitos ubicándose en $11,2 \%$ en promedio para 2016. La tasa de pobreza monetaria pasaría de $31 \%$ en 2013 a $34 \%$ en 2016 y solo hasta 2020 volvería a ubicarse cerca al $30 \%$. Dicen los autores que dichas tasas podrían ser aún más altas si programas como Familias en Acción ven su presupuesto recortado.

El impacto de un modelo de crecimiento basado en recursos no renovables y de escasa generación de valor agregado sobre las posibilidades degeneración de empleo, de lucha contra la pobreza y de políticas sociales sostenibles es evidente. Más allá de la necesidad de salir de un enfoque micro de lucha contra la pobreza, por medio de mecanismos como la gestión social del riesgo, se trata de inscribir, como lo plantea Tendler (2004), tanto la política social como la generación de empleo en un espectro más amplio, vinculado al modelo de crecimiento y de desarrollo. Las formas que tome este último influyen sobre las posibilidades de extensión de la protección social, conexión que pasa por el aumento de la productividad que permite financiar los seguros sociales y cuyos costos obligan a las empresas a buscar ganancias por medio de mayores inversiones (GREITD, 1993).

\section{REFERENCIAS}

Banco Mundial (2015). Trabajar por el fin de la pobreza en América Latina y el Caribe. Trabajadores, empleos y salarios. Washington D.C.: Documento del Banco Mundial.

Barrientos, A. (2004). Latin America: Towards a Liberal-Informal Welfare Regime. En Insecurity and Welfare Regimes in Asia, Africa and Latin
America (pp. 121-168). Cambridge: Cambridge University Press.

Cecchini, S., Filgueira, F. y Robles, C. (2014). Sistemas de protección social en América Latina y el Caribe. Una perspectiva comparada. Santiago de Chile: Naciones Unidas.

Clavijo, S., Vera, A., Malagón, D., Vera, N. y Cabra, M. (2013). El pasivo pensional de Colombia. Cálculo de su valor presente neto y sensibilidades paramétricas. Bogotá D.C.: ANIF.

Colpensiones (2015). Instructivo afiliación empleadas domésticas. Bogotá D.C.: Normograma de la Administradora Colombiana de Pensiones Colpensiones.

CONPES 3144 (2001). Creación del Sistema social de riesgo y Fondo de protección social. Bogotá: Consejo Nacional de Política Económica y Social.

Decreto 2616 (2013). Por medio del cual se regula la cotización a seguridad social para trabajadores dependientes que laboran por periodos inferiores a un mes. Bogotá: Consejo Nacional de Política Económica y Social

Decreto 721 (2013). Por medio del cual se regula la afiliación de los trabajadores del servicio doméstico al Sistema de Compensación Familiar. Bogotá: Consejo Nacional de Política Económica y Social

Departamento Nacional de Planeación (2007). Plan de Desarrollo 2006-2010. Estado comunitario: desarrollo para todos. Bogotá D.C.: Departamento Nacional de Planeación.

Departamento Nacional de Planeación (2008). De la asistencia a la promoción social. Hacia un sistema de Promoción Social. Sistema de Indicadores Sociodemográficos para Colombia. Bogotá D.C.: Departamento Nacional de Planeación.

Durán Valverde, F., Flores, J., Ortiz, J., Muñoz, D., de Lima, A. C. y Tessier, L. (2013). Innovaciones en la extensión de la cobertura del seguro social 
a los trabajadores independientes. Experiencias de Brasil, Cabo Verde, Colombia, Costa Rica, Ecuador, Filipinas, Francia y Uruguay. Ginebra: Organización Internacional del Trabajo.

Esping-Andersen, G. (1990). The Three Worlds of Welfare Capitalism. Oxford: Polity Press.

Esping-Andersen, G. (1999). Social Foundations of Post-industrial Economies. Oxford: Oxford University Press.

Filgueira, F. (1999). Tipos de welfare y reformas sociales en América Latina: eficiencia, residualismo y ciudadanía estratificada. En Reforma do Estado e mudança institucional no Brasil. Fundação: Joaquim Nabuco.

Giraldo, C. (2007). Protection sociale et financiarisation: avec une étude de cas sur la Colombie [Tesis de Doctorado]. Paris: Universidad Sorbona.

Gough, I. (2004). Welfare Regimes in development contexts: a global and regional analysis. En Insecurity and Welfare Regimes in Asia, Africa and Latin America (pp. 15-48). Cambridge: Cambridge University Press.

Gough, I., Wood, G., Bevan, P., Davis, P. y Room, G. (2004). Insecurity and Welfare Regimes in Asia, Africa and Latin America. Cambridge: Cambridge University Press.

GREITD (1993). État et Protection sociales: une comparaison entre l'Europe et l'Amérique Latine. Cahiers des Amériques Latines (15), 135-150.

Holzmann, R. y Jorgensen, S. (2003). Manejo social del riesgo: un nuevo marco conceptual para la protección social y más allá. Revista de la Facultad Nacional de Salud Pública, 21 (1), 73-106.

Lautier, B. (2005a). Una protección social mutualista y universal: condición para la eficacia de la lucha contra la pobreza. En Sistemas de protección social: entre la volatilidad económica y la vulnerabilidad social (pp. 95-145). Bogotá D.C.: Universidad Nacional de Colombia.

Lautier, B. (2005b). A propos de la reforme de 'assurancemaladie en Colombie: universalisation d'un droit ou universalisation de l'accès à un marché? Réunion du groupe de travail "protection sociale". Paris: Réseau Impact.

Lautier, B., Miras, de C. y Morice, A. (1991). L'État et l'informel. Paris: L'Harmattan.

López, H. (2010). El mercado laboral colombiano: tendencias de largo plazo y sugerencias de politica, 606. Bogotá D.C.: Banco de la República.

López, H. (2014). El mercado laboral colombiano: dinámica de largo plazo y desempeño laboral creciente. Medellín: Universidad EAfIT.

Majid, N. (2001). The working poor in developing countries. International Labour Review, 140 (3), 271-291.

Martínez-Franzoni, J. (2008). Welfare regimes in LatinAmerican: capturing constellations of markets, families and policies. Latin-American Politics and Society, 50 (2), 67-100.

Merrien, F. X. (2013). La protection sociale comme politique de développement: un nouveau programme d'action international. International Development Policy. Revue internationale de politique de développement. Revue internationale de politique de développement, 4(2), 68-88.

Mesa Lago, C. (2008). Social Insurance (Pensions and Health), Labour Markets and Coverage in Latin America, Geneva, UNRISD, Social Policy and Employment Programme Papers. 36, August 2008.

Ministerio de Trabajo (2012). Ley que evita los abusos laborales contra los trabajadores de servicio doméstico es una realidad. Recuperado de http:// www.mintrabajo.gov.co

Observatorio del Mercado de Trabajo y de la Seguridad Social (omTss) (2001). Búsqueda de meno- 
res costos, calidad del empleo e informalidad.

Boletin 3. Bogotá: Universidad Externado de Colombia.

Organización Internacional del Trabajo (2011). Convenio 189. Trabajo decente para las trabajadoras y los trabajadores domésticos. Ginebra: Organización Internacional del Trabajo (огт).

Programa de las Naciones Unidas para el Desarrollo (2014). Colombia frente a una destorcida en los precios del petróleo. Bogotá: Cuadernos del PNUD.

Rodríguez, L. (2014). Consideraciones sobre el gasto público social. IM-Pertinente, 2 (2), pp. 129-169.
Sánchez, M. (2015). Identificación y caracterización de los trabajadores pobres en Colombia, 20022012. Revista de Economía Institucional, 17 (32), 295-315.

Soto Iguarán, C. (2011). The Turkish Welfare Regime under pressure: resilience or change? Région et développement (34), pp. 85-112.

Tendler, J. (2004). Why Social Policy is Condemned to a Residual Category of Safety Nets and What to Do About It. En Social Policy in a Development Context (pp. 119-42). Basingstoke: Palgrave. 